\title{
An Experimental Comparative Analysis of Twist Drilling, Helical Milling and Pilot Hole Machining for Large Diameters in CFRPs
}

\author{
Abubakar Yakubu Haruna ${ }^{1^{*}}$, Gong Dong Wang1,2* \\ ${ }^{1}$ School of Aerospace Engineering, Shenyang Aerospace University, Shenyang, China \\ ${ }^{2}$ Key Laboratory of Fundamental Science for National Defence of Aeronautical Digital Manufacturing Process, Shenyang \\ Aerospace University, Shenyang, China \\ Email: *yakubuharuna227@yahoo.com
}

How to cite this paper: Haruna, A.Y. and Wang, G.D. (2021) An Experimental Comparative Analysis of Twist Drilling, Helical Milling and Pilot Hole Machining for Large Diameters in CFRPs. Open Access Library Journal, 8: e7205.

https://doi.org/10.4236/oalib.1107205

Received: February 1, 2021

Accepted: March 22, 2021

Published: March 25, 2021

Copyright $\odot 2021$ by author(s) and Open Access Library Inc.

This work is licensed under the Creative Commons Attribution International License (CC BY 4.0).

http://creativecommons.org/licenses/by/4.0/

\begin{abstract}
Carbon fiber-reinforced polymer (CFRP) large diameter hole drilling is certifiably not a broadly examined theme on account of their non-homogeneity and anisotropic highlights. In the scope of aerospace industrial uses of this material, thousands of holes have to be machined for purposes of assembly. The quality of this machined hole is influenced adversely by matrix grid cratering, thermal damage, spalling, surface delamination, and material debasement or fiber pullout. Among these different deformities, delamination is considered the most severe for CFRP composite. The main objective of this work is to compare twist drilling, helical milling and pilot hole machining technologies concerning unidirectional CFRP composite. In addition, the force modules were also discussed. In the scope of this work, numerous machining experiments were conducted in unidirectional CFRP composite: herein the impact of the type of cutting tool and of process parameters on the quality of machined holes are analysed and discussed (diameter of holes, circularity error and characteristics of uncut fibres). In other to achieve a better hole quality, the Scanning electron microscope (SEM) analysis and evaluation of acquired data were conducted. Experimental results show holes machined using twist drilling method present the lowest-quality, with damages present at the tool entry and exit as compared to the other studied methods. This study intended to help in assisting technicians working on assembly large structural parts in aircraft or automobile industries in choosing the best hole machining procedure when this three are in consideration.
\end{abstract}

\section{Subject Areas}

Aerospace Engineering, Mechanical Engineering 


\section{Keywords}

CFRP Composite, Helical Milling, Thrust Force, Delamination, Hole Quality

\section{Introduction}

Carbon Fiber Reinforced Polymer (CFRP) composite materials are up to this point the most alluring material for aircraft structures and are expected to replace more than $50 \%$ of aircraft structures in future [1]. They are hard to cut materials in which the reinforced materials and the matrix segments show diverse mechanical properties. On the other hand, they are powerless against damages [2], which the most basic is delamination [3], as it causes $60 \%$ of the segment dismissal during assembling [4]. Generally, the composites are produced to a close net shape by means of the essential manufacturing procedures [5], which mainly focuses on aircraft load-bearing components [6]. Hole making is a fundamentally inescapable secondary manufacturing process in aircraft industry which is extensively performed to assemble materials [7] [8] [9]. There are several techniques of machining a hole, but in respect to this work, the author considers only twist drilling, helical milling and pilot hole.

Twist drilling is the most commonly used cutter as for structures and there has been considerable work in the area of twist drill performance. It is known that delamination at the hole exit is considered as the major defect during drilling of composite laminates. Ho-Cheng and Dharan [10] studied delamination in peel up and push down mechanism. Rahme et al. [11] showed the effect of the chisel edge on the critical thrust force and delamination when drilling thick composite material by using a twist drill bit. Hocheng et al. [12] presented the expression of the critical thrust force and delamination when carrying out twist drilling operation and other special drillings. According to UA Khashaba [13], the cracks at the exit of the holes were initiated under the chisel edge and propagated under the action of the two main cutting edges of twist drill bit. Numerous measures of preventing this major concern have been suggested, like the use of pre-drilled hole. Rahme and his co-workers [14] found that the use of pilot hole eliminated the effect of chisel edge and thus reduced the exit delamination.

Unlike twist drilling, helical milling process technique is one of the not long-ago proposed techniques to create hole with high accuracy. This method is defined with a cutting tool that moves in a spiral path. The cutting tool fabricates hole that is larger than the tool diameter. It is advantageous in terms of smooth cutting along operation, lower thrust force and high precision [7] [9] [15]. Compared with the traditional drilling method, the helical milling process not only has the superiority of reducing force and improving the quality of hole [8], but also can be allowed the attainment of hole with various diameters without changing the milling tool [16]. For this reason, it's been widely used as a process of making hole in hard to cut materials [17] [18]. 
The technique of pre-machining a hole plays an imperative role that commits a lot in the decrease of thrust force with chisel edge benefaction and it significantly reduces the threat of delamination. Tsao and Hocheng demonstrated that pilot hole (pre-drilling) process can be adopted in the drilling of various hole diameters of composite laminates with least delamination [19]. The work of the corresponding authors [19] [20] [21] showed that the use of pilot hole brought about a significant delamination reduction by eliminating the chisel edge effect and by reducing the thrust force responsible to remove the chips. Inter alia described by Rahme and his co-workers [22] found that the use of pilot hole eliminated the effect of chisel edge and thus reduction in the exit delamination. Won et al. presented an innovative model process for determining the effect of pre-drilling laminate with a pilot hole [23]. Brinksmeier and Janssen [24] used a two-step drilling multi-layered material of $\mathrm{AlCuMg}_{2} / \mathrm{CFRP} / \mathrm{Ti} 6 \mathrm{Al} 4 \mathrm{~V}$ by drilling a $6 \mathrm{~mm}$ pilot hole to a $16 \mathrm{~mm}$ diameter hole. Marques et al. [25] in his work emphasized that the use of pilot hole presented a good result enabling a $2 \%$ damage reduction when compared with the results of without a pilot hole. Qiu et al. [26] studied the effect of stepped drill pilot section on thrust force and hole wall damage. Wang and Kirwa [27] studied the best method of drilling between twist drill, pilot hole, and step drill methods to analyze the delamination and thrust force experimentally and by FE simulation.

The main objective of the present paper is to compare the three common large hole machining method (twist drilling, helical milling and pilot hole), that are mainly used in structures with high mechanical strength requirements in aircraft assembly, like the wing beam and fuselage beam. As hole making is a fundamentally inescapable secondary manufacturing process in aircraft industry which is extensively performed to assemble parts [7]. Conventionally parts are joined by use of bolts and rivets as they are important for fatigue life performance [8] [9]. But recently there are several techniques of machining a hole [28], in respect to this work the author considers three common ones use in making large diameter hole, as there has been other comparison studies on other hole machining methods, like Pereszlai et al. [28], where the authors compare wobble milling, helical milling and conventional drilling of CFRPs, but none to the author's knowledge has there attempted comparison analysis between twist drilling, helical milling and pilot hole in a single work, this necessitates the need for this comparison study as this hole machining methods are frequently in-use in aerospace industries. So, this study endeavors to carry out an experimental comparison of these three methods in other to see which method will present a machined hole with lesser delamination, a study like this can help in assisting technicians working on assembly large structural parts in aircraft or automobile industry in choosing the best hole machining method when this three are in consideration.

\section{Critical Force Modules}

The force modules establish the relationship between the cutting forces in hole 
machining process and the influential factors (such as tool geometry, tool wear, feed, and so on) which can help in optimizing the cutting parameters for a better hole quality.

\subsection{Twist Drill Force Module}

Amongst all hole machining operations listed in the introduction part of this paper, drilling using a twist drill is the most frequently applied in the aircraft industry for generating large holes. The mechanics of drilling composite materials has been examined along with the quality of the hole and the effect of tool design parameters. Hocheng et al. [12] presented the expression of the critical thrust force and delamination when carrying out twist drilling operation and other special drilling. They established the theoretical model of twist drill bit for the first time by using linear elastic fracture mechanics (LEFM) method. The thrust force (FA) leading the onset of delamination is modelled as a concentrated load along the central axis of drill bit in Figure 1. The center of the circular plate is loaded by a twist drill of diameter $\mathrm{d}$.

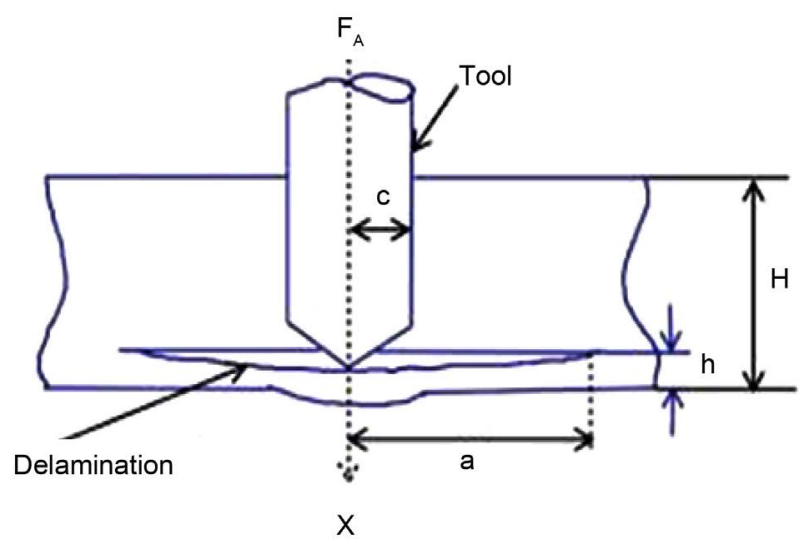

Figure 1. Model for delamination analysis for twist drill bit.

Below is a formula developed by Hocheng and Dharan [12] for a hole drilled straight without a pilot hole. The critical thrust force is given by:

$$
F_{A}^{*}=\pi\left[\frac{8 G_{I C} E h^{3}}{3\left(1-v^{2}\right)}\right]^{1 / 2}
$$

where $F_{A}^{*}$ is the critical thrust force, $E$ is the elastic modulus, $v$ is the Poisson ratio, $G_{I C}$ is the inter laminar fracture toughness and $h$ is the uncut plate thickness.

\subsection{Helical Milling Module}

In helical milling, the geometric relationship between tool and workpiece is different from traditional milling. Through following the helical path shown in Figure 2(a) below, holes can be machined with the aid of the helical milling tool. This operation is widely used to machine holes of CFRP composite in aerospace 
industry for its better hole-machining quality than traditional drilling operations. The relationship between milling force and cutting parameters has been investigated by researchers through experiments. Lipczynski G et al. [29] introduced some application of orbital drilling for the Boeing 787. WY et al. [30] studied the machining dynamics of orbital drilling and tooling solutions for different aerospace materials, i.e. CFRP composite materials, titanium alloy and aerospace aluminum alloy. D Boehnke et al. [31] studied the effect of feed on cutting forces during helical milling of CFRP-titanium layer.

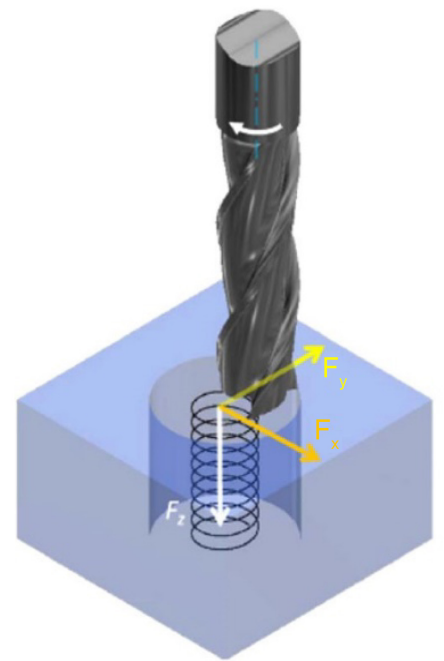

(a)

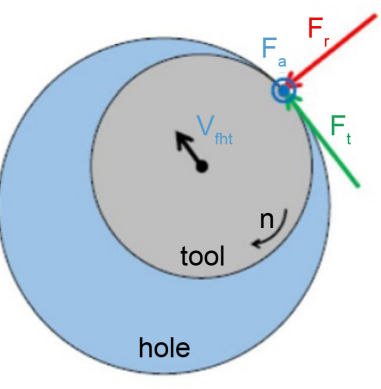

(b)

Figure 2. Cutting force components on (a) workpiece coordinate system; (b) tool coordinate system [32] [33].

Figure 2 show a simulation image, $n$ is the tool revolution angle which corresponds to the instant where the tooth with center-cut is on the borehole surface (aligned with) while $V_{f t t}$ represent the tangential feed speed. The forces $F_{t}$ $F_{r}$ and $F_{a}$ represent the actions applied on the tool during cutting.

To calculate the cutting forces in helical milling, the tool can be analyzed as a stack of disks, where each disk has $\mathrm{d} z$ thickness and a different radius. The elemental tangential $\mathrm{d} F_{t}$ radial $\mathrm{d} F_{r}$, and axial $\mathrm{d} F_{a}$ cutting forces [34] acting on flute of an "ideal" system (with a rigid cutter and zero eccentricity in the cutter axis of rotation) are given by:

$$
\left\{\begin{array}{l}
\mathrm{d} F_{t i}(\varnothing, z)=K_{t c} h_{i}(\varnothing, z) \mathrm{d} z+K_{t e} \mathrm{~d} S \\
\mathrm{~d} F_{r i}(\varnothing, z)=K_{r c} h_{i}(\varnothing, z) \mathrm{d} z+K_{r e} \mathrm{~d} S \\
\mathrm{~d} F_{a i}(\varnothing, z)=K_{a c} h_{i}(\varnothing, z) \mathrm{d} z+K_{a e} \mathrm{~d} S
\end{array}\right.
$$

The proposed linear models are based on the expressions presented by Altintas [35]. The cutting forces in Equation (1) are modeled in terms of two fundamental phenomena, an edge force component due to rubbing or plowing at the cutting edge represented by $K_{t e}, K_{r e}, K_{a e}$ on a unit width of cut basis, and a cutting component due to shearing at the shear zone and friction at the rake face, 
represented by $K_{t c}, K_{r c}, K_{a c}$ on a unit area of cut basis. These six cutting force coefficients are identified from specially devised milling tests and mechanistic analysis.

\subsection{Pilot Hole Force Module}

Nowadays, the commonly used method in order to drill holes for rivets and bolts assembly in thick composite structures is composed of three steps:

- Drilling of pilot hole,

- reaming of the hole (drilled with pilot hole),

- Countersinking the head of rivet or bolt.

Below is an analytical model of predicting critical thrust force when using a pilot hole which was developed by both Tsao and Hocheng [19] and Won and Dharan [23], from the model they developed an equation relating critical thrust force as a function of the material properties, the uncut thickness and the ratio of the chisel edge length to drill diameter (set to be the same as the pilot hole diameter).

$$
\begin{gathered}
F_{C T}=\frac{4 \pi}{1-\gamma}\left[\frac{G_{I C} E h^{3}\left\{(1-\gamma)+2(1-\gamma) \delta^{2}\right\}^{2}}{3(1-\gamma)\left\{2(1-\gamma)\left(1+2 \gamma^{2}\right)-\left(12-4 \gamma+3 \gamma^{2}+3 \gamma^{3}\right) \delta^{2}-8(1+3 \gamma) \delta^{2} \ln \delta\right\}}\right]^{\frac{1}{2}} \\
\delta=\frac{b}{R_{t}}
\end{gathered}
$$

where $G_{I C}$ is the critical energy release rate per unit area, $E$ is elastic modulus, $h$ is the uncut thickness, $\gamma$ is the Poisson ratio, $b$ is the radius of the pre-drilled hole, whereas $R_{t}$ is the radius of the drilling tool, then $\delta$ is the ratio of the radius of pre-drilled hole to radius of drilling tool. Determination of the pre-drilled hole radius relative to the radius of the drilling tool is of paramount importance as it determines the critical thrust force required and hence the extent of damage to the hole. Additionally, Meng et al. [35] developed a model to predict the fluctuation of thrust force during drilling of UD-CFRP. In their work the cutting lip is divided into a set of elements, as shown below. Figure 3 it illustrates the drilling of UD-CFRP using a twist drill and a pilot hole that was drilled on the workpiece to exclude the effect of chisel edge.

\section{Experimentation}

\subsection{Materials}

The material stacks used in this study are composed of composite. The composite specimen used in this investigation are $2 \mathrm{~mm}$ thick. The composite are composed of 16 unidirectional layers of $0.125 \mathrm{~mm}$ thickness each. The CFRP laminate was fabricated from the purchased unidirectional carbon fiber (Tenax HTS40 12 K 300) impregnated with (Cycom ${ }^{\circledR}$ 977-2) epoxy resin with a glass transition temperature (Tg) of $212^{\circ} \mathrm{C}$. The staking sequence used hand layup 
$\left[0^{\circ} / 90^{\circ}\right] 4 \mathrm{~s}$, for a total of 16 layers. The autoclave method was used for the curing process of the laminates. Aluminum 2024/T3 plate with a thickness of $2 \mathrm{~mm}$ was purchased from Yiwanhong International Trading Co., LTD. The overall dimensions of the workpiece were $(100 \times 100 \times 4) \mathrm{mm}$. The mechanical properties of the laminate and the aluminum were obtained from literature and are given in Table 1 and Table 2 respectively.

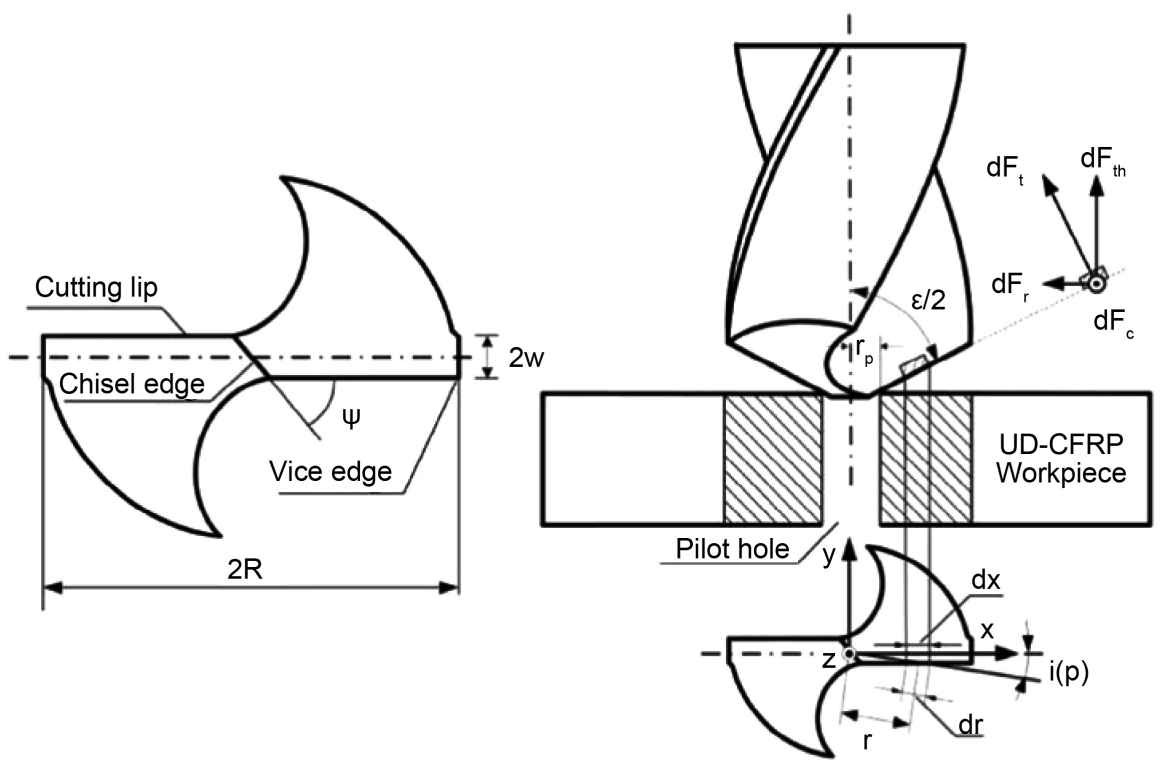

(a)

(b)

Figure 3. (a) The projection of the drill tip; (b) Force analysis during the drilling of UD-CFRP [36].

Table 1. Mechanical properties of the laminates.

\begin{tabular}{ccc}
\hline Property & Value & Units \\
\hline Density & 1600 & $\mathrm{~kg} / \mathrm{m}^{3}$ \\
$E_{1}$ & 153 & $\mathrm{GPa}$ \\
$E_{2}=E_{3}$ & 10.3 & $\mathrm{GPa}$ \\
$v_{12}=v_{13}$ & 0.3 & Dimensionless \\
$v_{23}$ & 0.4 & Dimensionless \\
$G_{12}=G_{13}$ & 6 & $\mathrm{GPa}$ \\
$G_{23}$ & 3.7 & $\mathrm{GPa}$
\end{tabular}

Table 2. Mechanical properties of Aluminum 2024-T3.

\begin{tabular}{ccc}
\hline Property & Value & Units \\
\hline Density & 2780 & $\mathrm{~kg} / \mathrm{m}^{3}$ \\
$E$ & 73.1 & $\mathrm{GPa}$ \\
$V$ & 0.33 & $\mathrm{GPa}$ \\
\hline
\end{tabular}




\subsection{Cutting Tools}

A three-flute solid carbide milling tool was utilized. The tool had a general length of $60 \mathrm{~mm}$, cutting edge length of $20 \mathrm{~mm}$, a measurement of $8 \mathrm{~mm}$ diameter, helix angle of $45^{\circ}$, a clearance angle of $20^{\circ}$ and a rake angle of $9^{\circ}$. So as to kill the effects of tool wear on the outcomes, new tool was use for each smallest case appearance of tool wear. For comparison with conventional drilling, a Titanium aluminum nitride (TiAlN) solid carbide drill bit of diameter $5 \mathrm{~mm}$ for pilot hole and a solid carbide twist drill tool with a cross-section diameter of $12 \mathrm{~mm}$ were use. The twist drill bit has an overall length of $70 \mathrm{~mm}$, point angle of $140^{\circ}$ and helix angle of $30^{\circ}$. The instruments are appeared in Figure 4 below (a), (b) and (c) respectively.

(a)

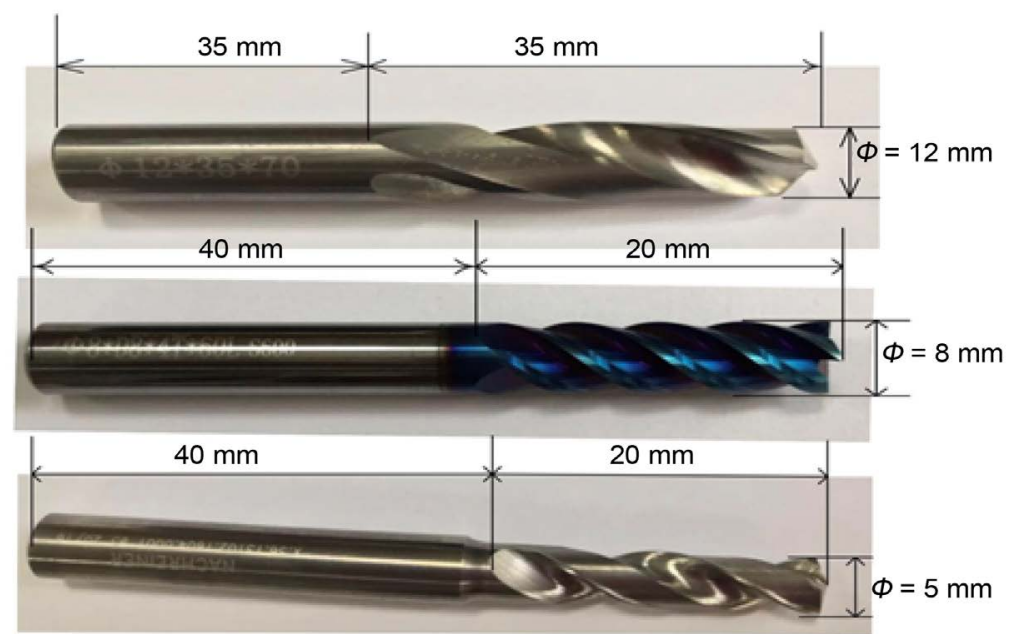

Figure 4. (a) Twist drill tool, (b) Helical milling tool and (c) pilot hole drill tool.

\subsection{Drilling Experiment}

The drilling tests were done at the Liaoning Province key research facility for composite structural analysis. A Computer Numerical Control (CNC) processing machine type XKA714C was use for the milling tests. A Kistler dynamometer type 9273 was use to record the force involve during the drilling procedure. The forces, which are recorded in form of electrical signals, are then enhanced by a Kistler type $4624 \mathrm{AK}$ amplifier before being passed to a PC where the Dynoware software helps in securing and assessment of the cutting powers. The estimation measurement was gotten at a frequency of 500 all through the drilling procedure. An exceptionally structured workpiece holding component was used to hold the CFRP stack set up during the tests. The mechanism is part into two parts with securing nuts that hold the workpiece solidly in the middle of them. Three spindle speed $(1000,2000,3000 \mathrm{r} / \mathrm{min})$ and three feed rates of (5, 10 and $15 \mathrm{~mm} / \mathrm{min}$ ) were chosen for this study (Table 3). In the initial step, 10 $\mathrm{mm}$ diameter hole is made on the CFRP laminate using helical milling and another $10 \mathrm{~mm}$ diameter is also made on a different CFRP laminate using conventional drilling. The holes were then later enlarged to $12 \mathrm{~mm}$ diameter in the 
second step. In the case of the pilot hole, $5 \mathrm{~mm}$ diameter pre-drilled hole is first made then the hole is enlarged to $12 \mathrm{~mm}$ diameter with by using larger $(12 \mathrm{~mm})$ drilled bit. Figure 5 shows the schematic of experimental set-up.

Table 3. Cutting parameters.

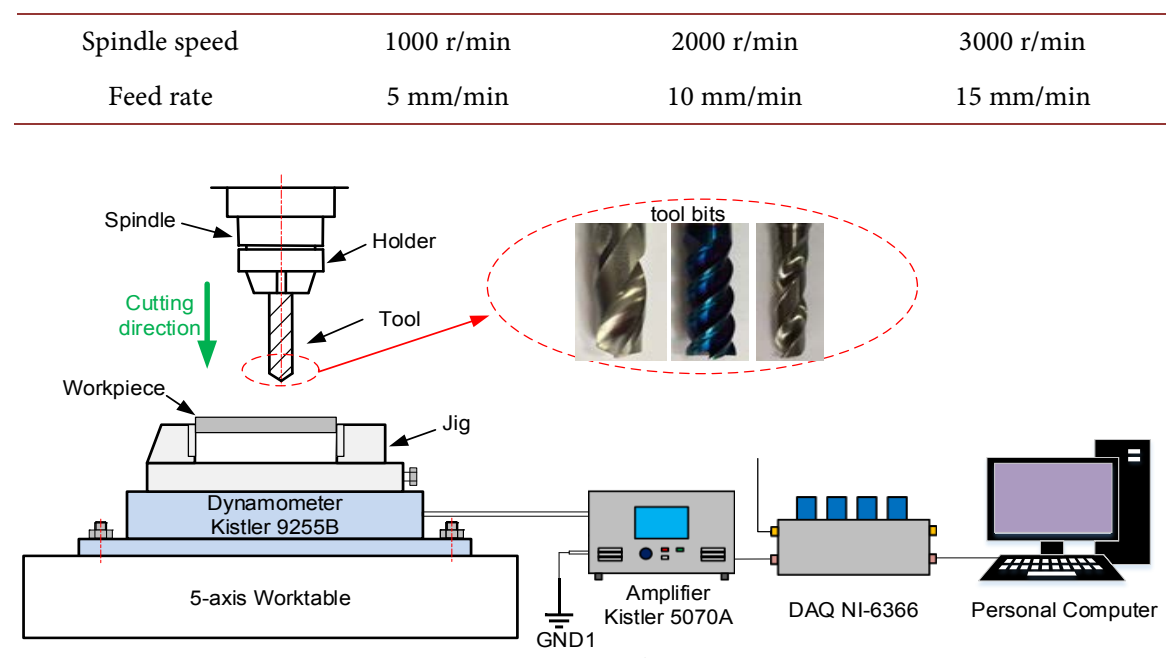

Figure 5. The schematic of experimental set-up.

\section{Results and Discussion}

\subsection{Thrust Force}

Studies involving machining processes especially hole manufacturing in composite laminates must closely monitor the thrust forces during the process. This is because thrust forces have been found to closely correlate with the level of damage on the workpiece. Because the thrust force will increase with the drilling contact area and affect mostly by feed rate. So, different feed rates were assigned for different drilling procedure in other to observe how the tools behave. Graphical approach from Figures 6-8, shows the thrust force plotted against time for twist drilling $(5 \mathrm{~mm} / \mathrm{min})$, helical milling $(10 \mathrm{~mm} / \mathrm{min})$ and pilot hole $(15$ $\mathrm{mm} / \mathrm{min}$ ) feed rates at various spindle speed. From both the three holes making strategies graphs, the author discovered the lower spindle speed $(1000 \mathrm{r} / \mathrm{min})$ to display the highest thrust force in all the graphs despite them having different feed rates. Thrust force found to decrease as spindle speed increases. The highest spindle speed $(3000 \mathrm{r} / \mathrm{min}$ ) displayed the lowest thrust force.

Figure 6 shows the behavior of the thrust force when drilling composite sandwich using the twist drill bit to make a $12 \mathrm{~mm}$ large hole. The details of the three stages in thrust force generation while using a carbide tool. Point (A) denote the place of the initial contact of the tool with the workpiece surface. Then from point (A-B) represent the advancement of the tool from the point of initial to a distance (drill point angle) where the tool gets fully engaged with the workpiece. The rise in thrust force from (A-B) was observed due to the extrusion action of the chisel edge. Thrust force seen to reach its maximum when conical surface of the tool and workpiece are fully engaged. Then from point (B-C) 
represent the disengagement period, when the cutting tool drilled through and the contact area is becoming less (after depth of $2 \mathrm{~mm}$ ). The tool tip cleared the bottom surface of the work material bringing down the thrust force gradually to Zero.

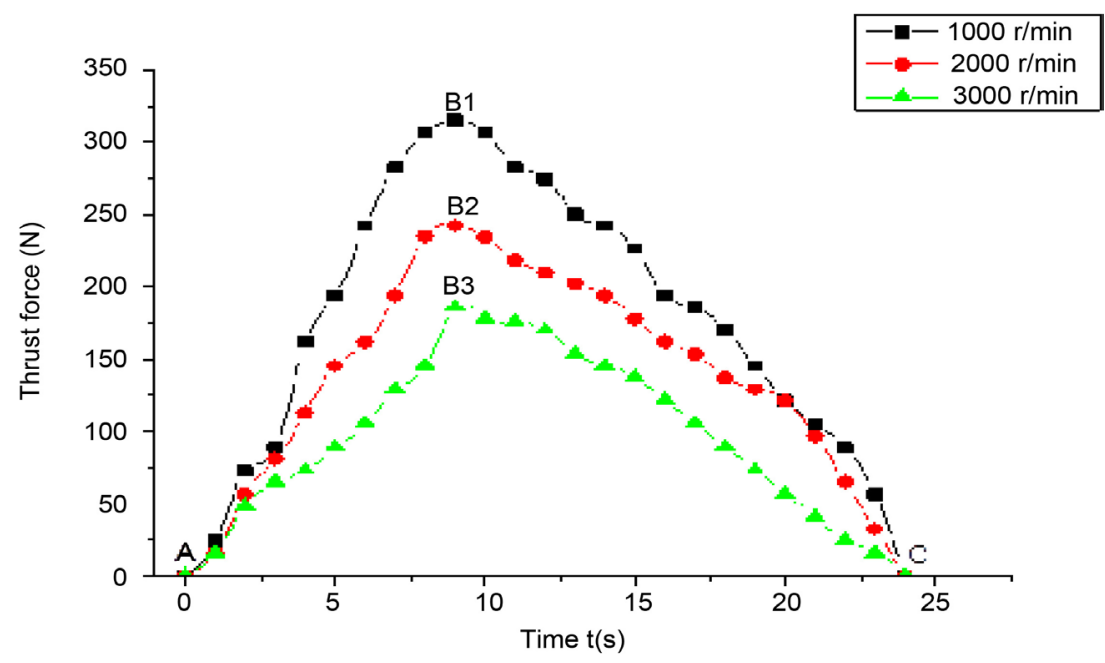

Figure 6. Thrust forces against time for Twist drilling at $5 \mathrm{~mm} / \mathrm{min}$ feed rate.

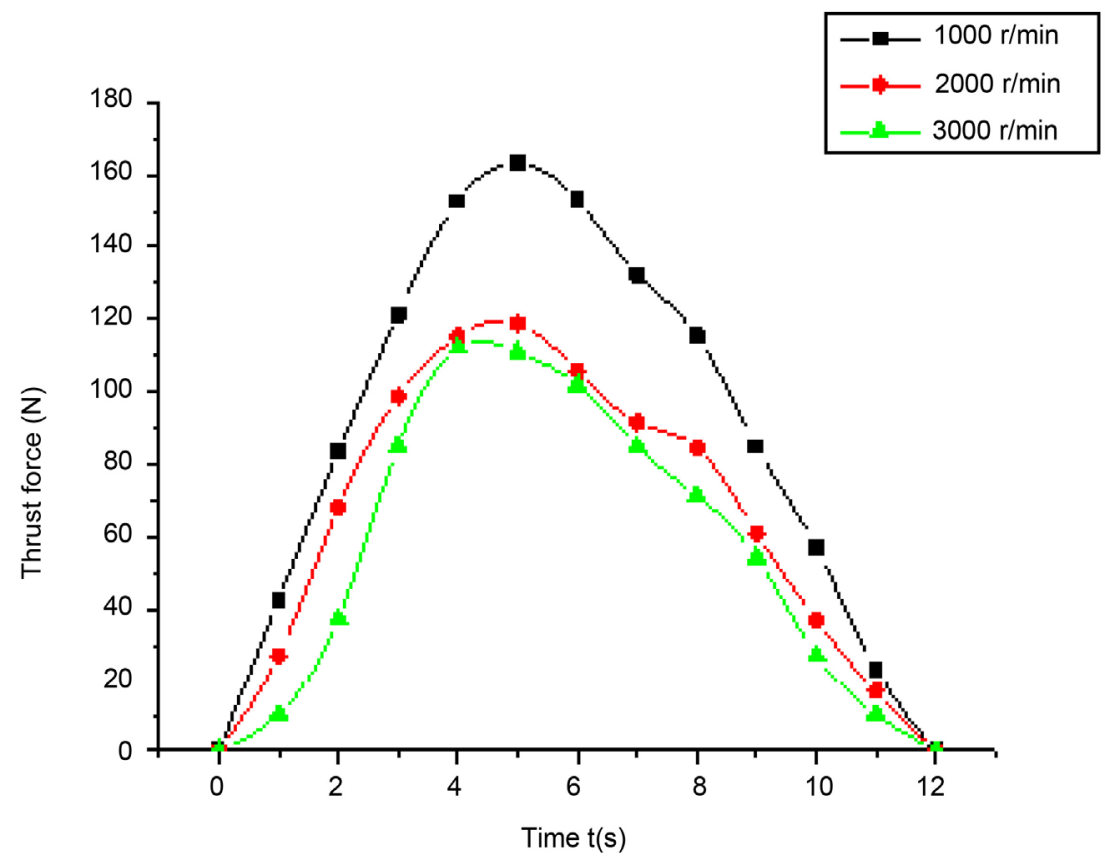

Figure 7. Thrust forces against time for Helical milling at $10 \mathrm{~mm} / \mathrm{min}$ feed rate.

In Figure 7, the use of a three-flute solid carbide milling tool was implored in making a hole by helical milling process. Three different spindle speeds and one axial feed rate of $10 \mathrm{~mm} / \mathrm{min}$ were selected for the helical milling, in other to study it is effect on the axial thrust force, and the result was graphically shown. Based on the kinematics of helical milling process, two features that could influence the cutting force and dynamics of the helical milling process were consi- 
dered. One was the periodical force variation created by the circle or tangential feed of the tool; the other is the additional force component generated by the axial feed of the tools. The axial feed force mostly occurred at the end cutting edge (end cutting edge) of the milling tool. The interaction condition between the tool and the workpiece is the combination of side edge cutting force and end edge cutting force.

Figure 8 contained two phases, with the first phase starting-ending and the second phase begins. The first phase illustrated or displayed a pilot hole drilling process while the second phase displayed the process for the enlarger hole that was drilled on the pre-drilled pilot hole to achieve the final $12 \mathrm{~mm}$ diameter. The pilot hole uses a drilled bit of $5 \mathrm{~mm}$ while the larger drill bit was $12 \mathrm{~mm}$. Pilot hole done to suppress the effect of delamination by eliminating the chisel edge effect and reducing the thrust force. The experiment was carried out using 1000 $\mathrm{r} / \mathrm{min}, 2000 \mathrm{r} / \mathrm{min}$ and $3000 \mathrm{r} / \mathrm{min}$ spindle speed, all at feed rate of $15 \mathrm{~mm} / \mathrm{min}$. The lower spindle speed shows the higher thrust force.

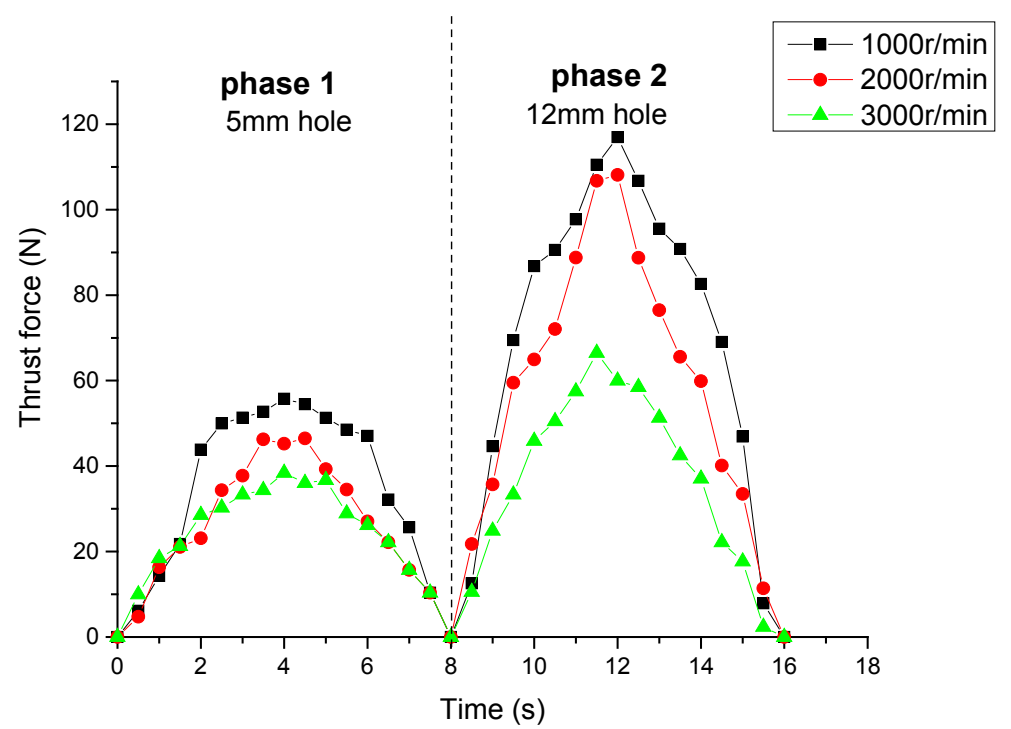

Figure 8. Thrust forces against time for Pilot hole at $15 \mathrm{~mm} / \mathrm{min}$ feed rate.

An interestingly point to note about twist drilling, even though the lowest feed rate $(5 \mathrm{~mm} / \mathrm{min})$ was selected, the thrust force still expressed the highest value, that means twist drill was unsuitable for large hole machining.

On the other side, in other to assest the defect that occurs as the result of the drilling, especially the surface morphology of holes, the SEM analysis was use to record the defects. Table 4 describes the typical defects observed in the holes. It can be seen from the comparison of the surface morphologies that refinement of the tool materials and the higher rotation speed of the cutting lips offer a better surface morphology, and the damages at the holes exit are more impressive than the entrance. In addition, the fiber pullout and the delamination also exist at the inter-laminates occasionally, depending on the drilling parameters and the cutting capability of the tools. 


\subsection{Comparison of Twist Drilling, Helical Milling and Pilot Hole Drilling}

A comparison analysis between twist drilling, helical milling and pilot hole. By analyzing the drilling results of delamination factors with feed rates, thrust force and cutting speed some significant optimization methodology can be established. Monitoring of thrust forces during hole manufacturing in composite laminates is crucial for damage analysis, as thrust forces have been found to correlate with delamination damage. Similar drilling parameters of $1000 \mathrm{r} / \mathrm{min}$, $2000 \mathrm{r} / \mathrm{min}$ and $3000 \mathrm{r} / \mathrm{min}$ spindle speeds and $15 \mathrm{~mm} / \mathrm{min}$ axial feed rate were applied to both the three large hole manufacturing processes. In both cases, the axial forces were recorded and plotted against the drilling time of the CFRP as seen in (Figure 9). Over the entire drilling, hole manufacturing by the helical milling method records about $35 \%$ less thrust force compared to conventional drilling. This is expected since helical milling uses both peripheral and axial cutting in the distribution of forces unlike conventional drilling where there is only axial cutting thrust drilling tool acting like a point load elevating the thrust force. The use of pilot hole in the experiment has seen to brings about a significant delamination reduction by eliminating the chisel edge effect and by reducing the thrust force responsible for removing the chips. The use of pilot hole $(5 \mathrm{~mm})$ associated with an enlarge drill bit $(12 \mathrm{~mm})$ presented a good result enabling a damage reduction when compared to a without pilot hole (twist drilling). When drilling hole of twist drilling (large hole), delamination at the hole exit was given a major concern as it is the defect more prone to happen during twist drilling operation. In some component during the operation, the cracks at the exit of the holes initiate under the chisel edge and propagated under the action of the two main cutting edges of the twist drill bit.

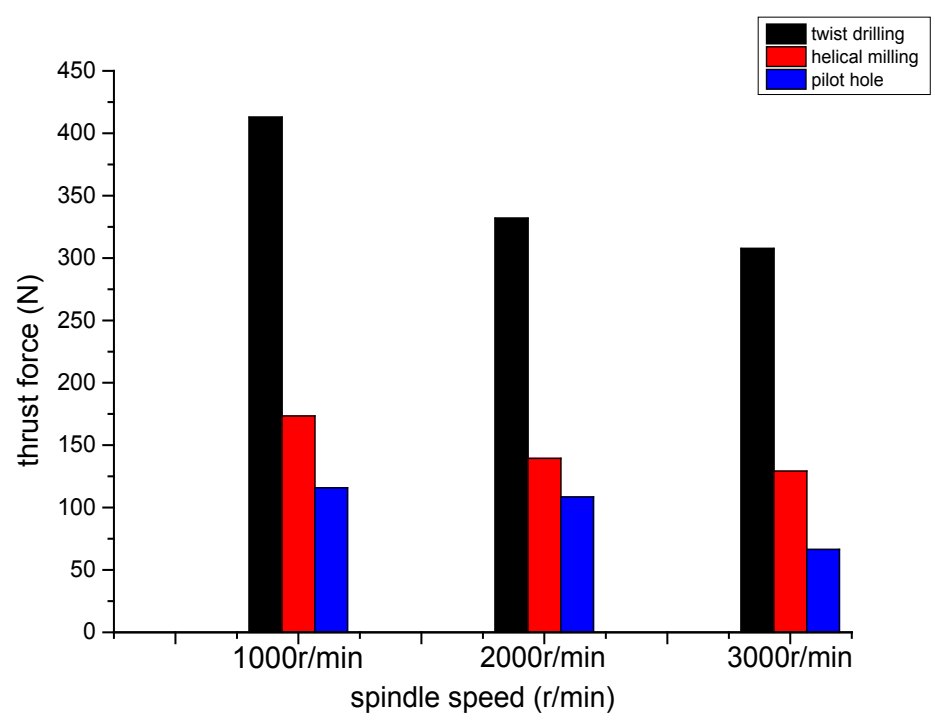

Figure 9. Thrust forces against spindle speed at $15 \mathrm{~mm} / \mathrm{min}$ feed rate.

In Figure 9, the pilot hole section displayed the thrust forces of (116.96, 
108.12, 66.49) $\mathrm{N}$, for the enlarger hole that was drilled on the pre-drilled pilot hole to achieve the final $12 \mathrm{~mm}$ diameter, all on the spindle speeds of 1000 $\mathrm{r} / \mathrm{min}, 2000 \mathrm{r} / \mathrm{min}$ and $3000 \mathrm{r} / \mathrm{min}$ respectively. The initial Pilot hole was drilled to suppress the effect of delamination by eliminating the chisel edge effect, and as seen from Figure 9, it significantly reduces the thrust forces compared to the none pilot hole one (twist drilling).

\subsection{Hole Quality}

After laminate holes are drilled, it is important to establish criteria to compare the hole delamination extension caused by different machining processes in an easy way. The damage to the hole during manufacturing commonly occurs both at tool entry and tool exit known in the research field as peel-up and push-down delamination respectively. Damage extension can be evaluated through non-destructive testing (NDT). Some examples are: the use of a tool maker's microscope, ultrasound techniques [37], acoustic emission [38], enhanced radiography [39] [40]. In this work, Scanning Electron Microscope (SEM) was employed to examine the quality of the machined holes both at entry and CFRP interface. The possibility of carrying out the quantification of the damaged region to calculate a factor that numerically expresses the damaged region extension and shape was presented in the work of Chen [41], He presented a comparing factor that enables the evaluation and analysis of delamination extent in laminated composites. The ratio was called the delamination factor. Figure 10 illustrates how to measure the maximum and nominal diameters in a delaminated hole.

$$
F_{d}=\frac{D_{\max }}{D_{\text {nom }}}
$$

The factor, expressed as $F_{d}$ is the ratio of maximum diameter in the damaged zone expressed as $D_{\max }$ to the hole diameter expressed as $D_{\text {nom }}$ shown in Equation (5) above.

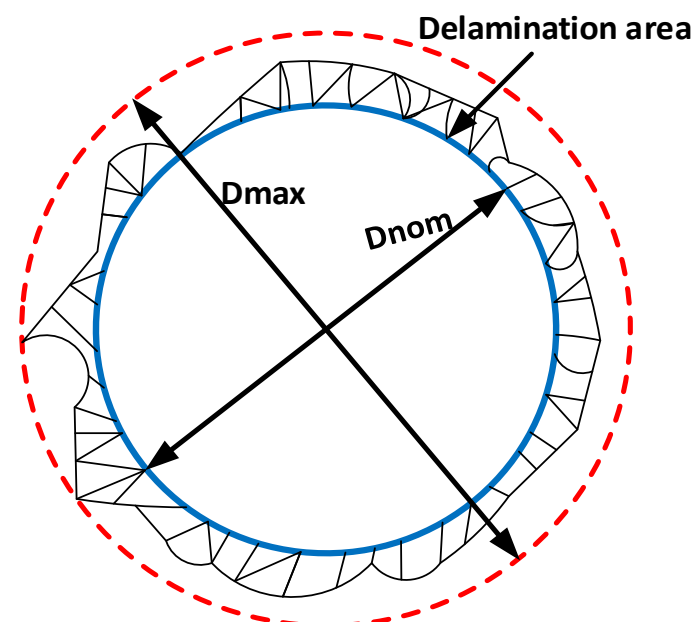

Figure 10. Delamination factor measurement. 
Thrust forces which relate to the extent of damage on the composite laminates, have been captured in the experiments. In order to analyze the damage on the hole, the drilled composite plates were examined using the SEM. The entry and exit damages on the holes were noted including delamination and uncut fibers as shown in Table 4. The drilling by a twist drill is seen (Table 4) to experience much damage especially at the drill exit and entry compared to other methods studied. Some delamination and uncut fibers are seen to dominate the hole exit part of the plate. The holes of pilot drilling and Helical milling shows better quality and good damage resistance both at entry and exit parts of the holes. As already mentioned, the delamination factor proposed by Chen was further used to quantify the extent of damage in these layers. The ratio, which relates the maximum delaminated diameter to the nominal diameter, is shown in Figure 10 for each of the drilling method studied. Results of quantitative analysis using delamination factor is shown in Table 4. And the three large hole making procedures comparison shows that, holes achieved by twist drilling have the largest delamination factors.

Table 4. SEM micrographs of typical defects on the holes.

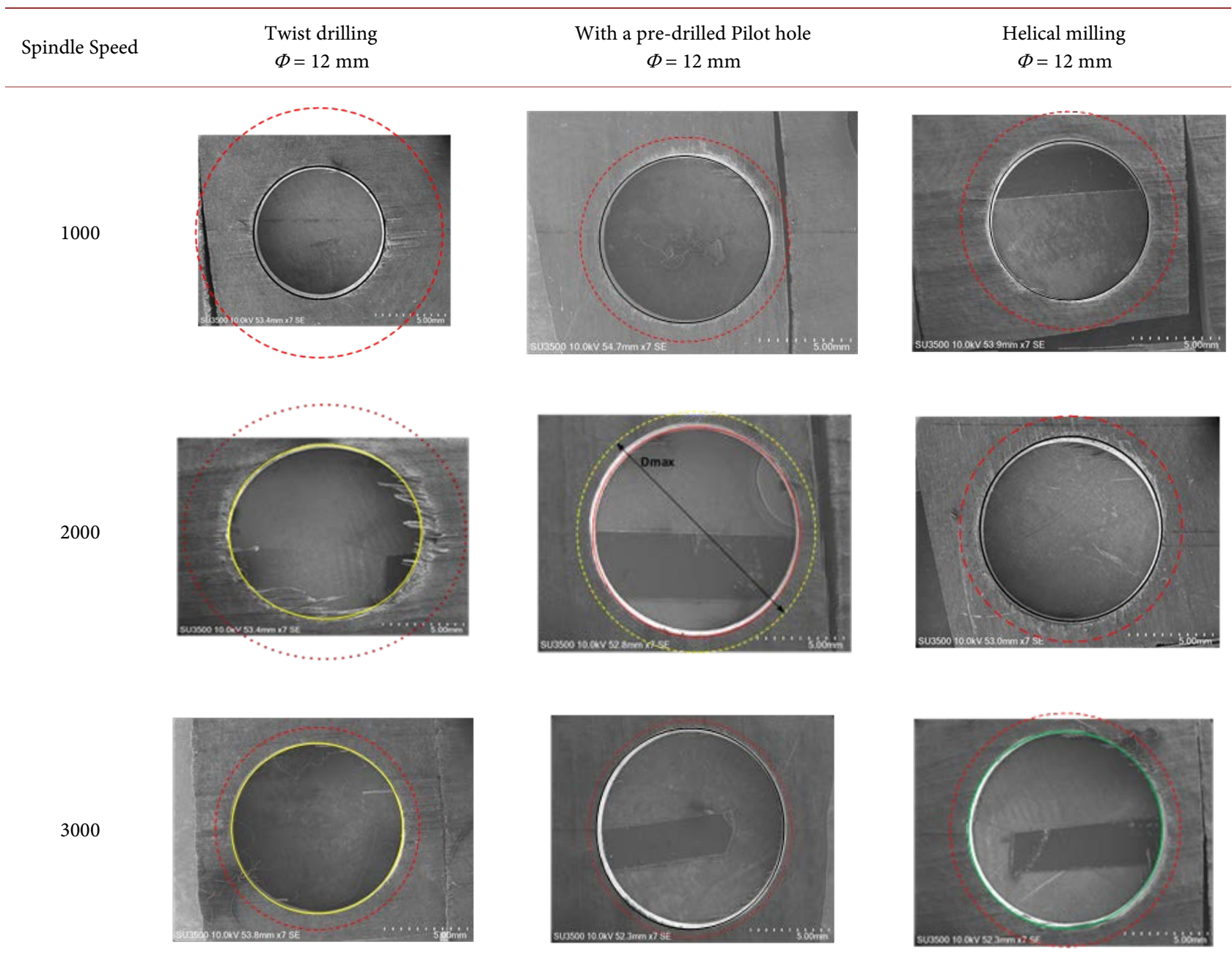




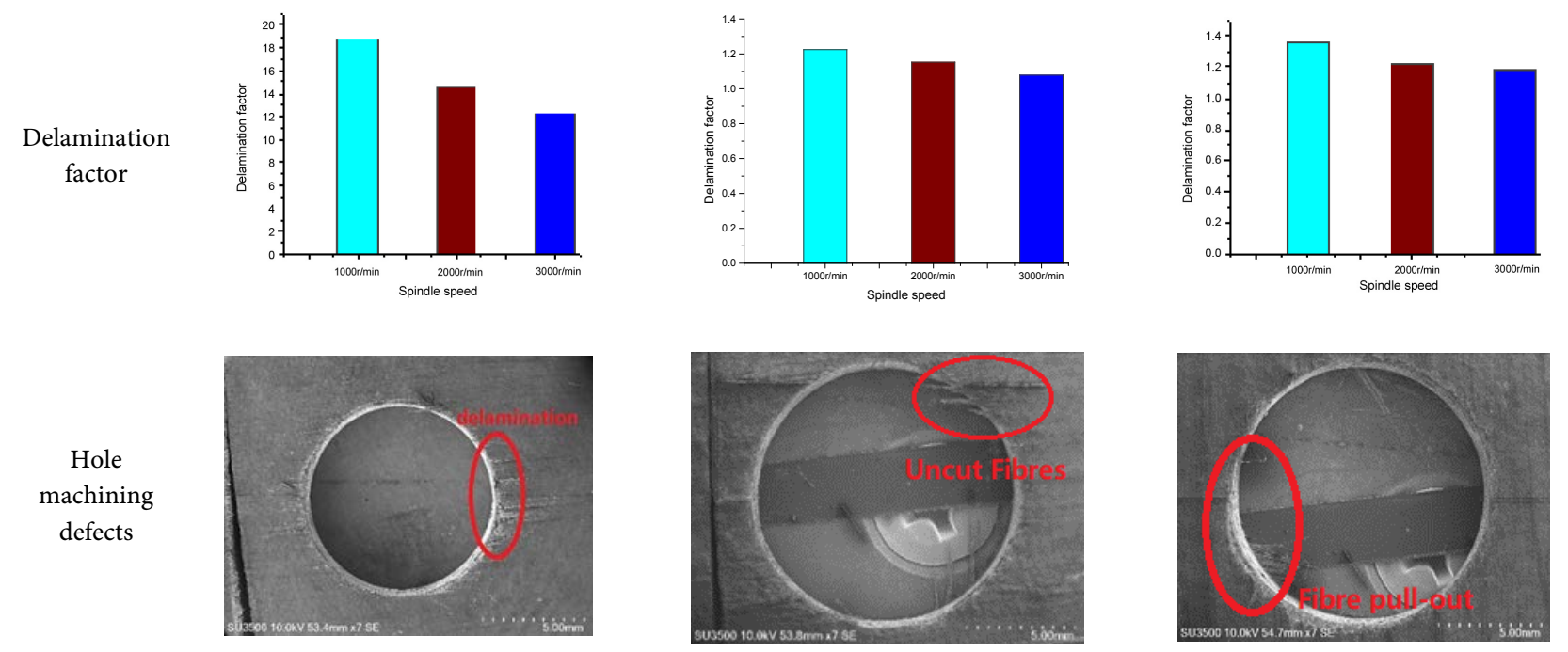

\section{Conclusions}

The research work is accomplished for $12 \mathrm{~mm}$ hole diameter, of hand-laminated $2 \mathrm{~mm}$ thick UD-CFRP by using three diverse drilling procedures: helical milling, twist drilling and pilot hole drilling respectively. In the experimental analysis, drilling speed and feed rate differs accordingly. The holes were machined and analyzed to decide among the three procedures, which one will best be resulted in the lowest delamination factor, which mean a better hole quality. After carrying out the experimental studies, the following conclusion can be drawn from:

- Reduction in thrust force was noticed during operations for all the tool type (helical bit and twist bit) with rising in spindle speed. This is due to the reduction in coefficient of friction and material hardness as a result of temperature at higher spindle speeds. But thrust force was found to increase with increase in feed rates from $5 \mathrm{~mm} / \mathrm{min}, 10 \mathrm{~mm} / \mathrm{min}$ to $15 \mathrm{~mm} / \mathrm{min}$.

- Twist drilling displayed the highest thrust force and more delamination when compared to helical milling and pilot hole. It is tool of continuous flutes with higher angle causing the pulling action of the extreme top and bottom plies of the laminate which results in delamination.

- For the large hole with a pre-drilled pilot hole, from the experimental result, the percentage reduction in thrust forces seems very high compared to the large hole (twist drilling) achieved without a pre-drilled hole, even at higher spindle speed of $3000 \mathrm{r} / \mathrm{min}$ and feed rate of $15 \mathrm{~mm}$.

- The drilling by a twist drill is seen to experience much damage especially at the drill exit compared to other methods studied. Some delamination and uncut fibers dominate the hole exit part of the plate.

- The author noticed that at the point when the spindle speed was at the most critical, both helical milling and pilot hole drilling had brought down the delamination factor, implying that when the thrust force is at the least, the 
quality of the hole is better.

- When carrying out the drilling operation, feed rate and spindle speed become the main factors that affect the size of the hole wall damage. The damage area was seen to decrease as the feed rate increases, but it increases as the spindle speed increases.

- It was discovered that both in pilot hole and helical milling at spindle speed of $1000 \mathrm{r} / \mathrm{min}$, feed rate of $15 \mathrm{~mm} / \mathrm{min}$, the most extreme delamination and thrust force of $55.76 \mathrm{~N}$ and $173.4 \mathrm{~N}$ occurs.

- For the large hole that was drilled on the pilot hole, the authors noticed it to be quicker than the direct drilling and helical milling, affirming that using a pre-center drill hole during high mechanical strength part assembling (wing beam or fuselage beam), can save lead-time and subsequently production cost.

\section{Acknowledgements}

We would like to show our appreciation to Shenyang Aerospace University, Key Laboratory of Fundamental Science for National Defense of Aeronautical Digital Manufacturing Process and Liaoning Key Laboratory of Advanced Polymer Matrix Composites Manufacturing Technology for supporting the research activity.

\section{Funding}

Foundation of Liaoning Educational Committee No. L201734. Key Program of Natural Science Foundation of Liaoning Province of China No. 20170520019.

\section{Conflicts of Interest}

None declared.

\section{References}

[1] Soutis, C. (2005) Fibre Reinforced Composites in Aircraft Construction. Progress in Aerospace Sciences, 41, 143-151. https://doi.org/10.1016/j.paerosci.2005.02.004

[2] Durão, L.M.P., Gonçalves, D., Tavares, J.M.R.S., de Albuquerque, V.H.C., de Aguiar Vieira, A.M.R. and Baptista, A.P.M. (2014) Delamination in Carbon/Epoxy Plates Drilling: Tool and Feed Rate Effect. International Journal of Materials and Product Technology, 49, 267-284. https://doi.org/10.1504/IJMPT.2014.064935

[3] Liu, D., Tang, Y. and Cong, W.L. (2012) A Review of Mechanical Drilling for Composite Laminates. Composite Structures, 94, 1265-1279. https://doi.org/10.1016/j.compstruct.2011.11.024

[4] Makhdum, F., Roy, A., Silberschmidt, V.V. and Phadnis, V.A. (2013) Drilling in Carbon/Epoxy Composites: Experimental Investigations and Finite Element Implementation. Composites Part A: Applied Science and Manufacturing, 47, 41-51. https://doi.org/10.1016/j.compositesa.2012.11.020

[5] Balasubramanian, K., Sultan, M.T.H. and Rajeswari, N. (2018) Manufacturing Techniques of Composites for Aerospace Applications. In: Jawaid, M. and Thariq, M., Eds., Sustainable Composites for Aerospace Applications, Elsevier, Amsterdam, 55-67. https://doi.org/10.1016/B978-0-08-102131-6.00004-9 
[6] Xu, J., Mkaddem, A. and El Mansori, M. (2016) Recent Advances in Drilling Hybrid FRP/Ti Composite: A State-of-the-Art Review. Composite Structures, 135, 316-338. https://doi.org/10.1016/j.compstruct.2015.09.028

[7] Tonshoff, H., Friemuth, T., Andrae, P. and Groppe, M. (2000) Circular Milling Replacing Drilling and Reaming. Proceedings of II International Seminar on Improving Machine Tool Performance, 3-5 July 2000, Nantes-La Baule, France, 18 Seiten.

[8] Wang, G.D., Melly, S.K., Li, N., Peng, T. and Li, Y. (2018) Research on Milling Strategies to Reduce Delamination Damage during Machining of Holes in CFRP/Ti Stack. Composite Structures, 200, 679-688.

https://doi.org/10.1016/j.compstruct.2018.06.011

[9] Shan, Y., He, N., Li, L., Zhao, W. and Qin, X. (2011) Orbital Milling Hole of Aerospace Al-Alloy with Big Pitch. Transactions of Tianjin University, 17, 329-335. https://doi.org/10.1007/s12209-011-1637-x

[10] Tsao, C.C. and Hocheng, H. (2005) The Path towards Delamination-Free Drilling of Composite Materials. Journal of Materials Processing Technology, 167, 251-264. https://doi.org/10.1016/j.jmatprotec.2005.06.039

[11] Rahmé, P., Landon, Y., Lagarrigue, P., Piquet, R. and Lachaud, F. (2008) Study into Causes of Damage to Carbon Epoxy Composite Material during the Drilling Process. International Journal of Machining and Machinability of Materials, 3, 309-325. https://doi.org/10.1504/IJMMM.2008.020966

[12] Hocheng, H. and Dhara, C.H.K. (1990) Delamination during Drilling in Composite Laminates. Journal of Engineering for Industry, 112, 236-239.

https://doi.org/10.1115/1.2899580

[13] Khashaba, U.A. (2012) Drilling of Polymer Matrix Composites: A Review. Journal of Composite Materials, 47, 1817-1832.

[14] Rahmé, P., Landon, Y., Lagarrigue, P., Piquet, R., Lachaud, F., Marguet, B., Bourriquet, J. and Le Roy, C. (2009) Chisel Edge Effect on Delamination When Drilling Thick Composite Materials with a Twist Drill. SAE International Journal of Aerospace, 1, 776-781. https://doi.org/10.4271/2008-01-2301

[15] Iyer, R., Koshy, P. and Ng, E. (2007) Helical Milling: An Enabling Technology for Hard Machining Precision Holes in AISI D2 Tool Steel. International Journal of Machine Tools and Manufacture, 47, 205-210. https://doi.org/10.1016/j.ijmachtools.2006.04.006

[16] Liu, Y.P., Wang, F.J., Jing, X.B., Zhang, D.W., Liu, X.P. and Tian, Y.L. (2017) Modeling and Analyses of Helical Milling Process. The International Journal of Advanced Manufacturing Technology, 90, 1003-1022. https://doi.org/10.1007/s00170-016-9418-2

[17] He, N., Li, L., Zhao, W., Yang, Y.F. and Shan, Y.C. (2013) Vector Modeling of Robotic Helical Milling Hole Movement and Theoretical Analysis on Roughness of Hole Surface. Journal of Central South University, 20, 1818-1824.

https://doi.org/10.1007/s11771-013-1678-5

[18] Reis, L.R., Cunha, A.A., Paulo, P.A., Roberto, F.J., Paulo, D.J. and Dutra, P.R.B. (2017) Multi-Objective Robust Optimization of the Sustainable Helical Milling Process of the Aluminum Alloy Al 7075 Using the Augmented-Enhanced Normalized Normal Constraint Method. Journal of Cleaner Production, 152, 474-496. https://doi.org/10.1016/j.jclepro.2017.03.121

[19] Tsao, C.C. and Hocheng, H. (2013) The Effect of Chisel Length and Associated Pilot Hole on Delamination When Drilling Composite Materials. International Journal of Machine Tools and Manufacture, 43, 1087-1092. 
https://doi.org/10.1016/S0890-6955(03)00127-5

[20] Tsao, C.C. (2006) The Effect of Pilot Hole on Delamination When Core Drill Drilling Composite Materials. International Journal of Machine Tools and Manufacture, 46, 1653-1661. https://doi.org/10.1016/j.ijmachtools.2005.08.015

[21] Tsao, C.C. (2007) Effect of Pilot Hole on Thrust Force by Saw Drill. International Journal of Machine Tools and Manufacture, 47, 2172-2176. https://doi.org/10.1016/j.ijmachtools.2007.05.008

[22] Landon, Y., Piquet, R., Lachaud, F., et al. (2014) Drilling of Thick Composite Structures with Pilot Hole Using a Twist Drill. 16th European Conference on Composite Materials, Seville, 22-28 June 2014.

[23] Won, M.S. and Dharan, C.K.H. (2002) Chisel Edge and Pilot Hole Effects in Drilling Composite Laminates. Journal of Manufacturing Science and Engineering, Transactions of the ASME, 124, 242-247. https://doi.org/10.1115/1.1448317

[24] Brinksmeier, E. and Janssen, R. (2002) Drilling of Multi-Layer Composite Materials Consisting of Carbon Fiber Reinforced Plastics (CFRP), Titanium and Aluminum Alloys. CIRP Annals-Manufacturing Technology, 51, 87-90. https://doi.org/10.1016/S0007-8506(07)61472-3

[25] Marquestal, A.T., Durao, L.M., Magalhaes, A.G., et al. (2009) Delamination Analysis of Carbon Fibre Reinforced Laminates: Evaluation of a Special Step Drill. Composites Science and Technology, 69, 2376-2382. https://doi.org/10.1016/j.compscitech.2009.01.025

[26] Qiu, X.Y., Li, P.N., Niu, Q.L., Chen, A.H., et al. (2018) Influence of Machining Parameters and Tool Structure on Cutting Force and Hole Wall Damage in Drilling CFRP with Stepped Drills. The International Journal of Advanced Manufacturing Technology, 97, 857-865. https://doi.org/10.1007/s00170-018-1981-2

[27] Wang, G.D. and Kirwa, M.S. (2017) Comparisons of the Use of Twist, Pilot-Hole and Step-Drill on Influence of Carbon Fiber-Reinforced Polymer Drilling Hole Quality. Journal of Composite Materials, 52, 1465-1480. https://doi.org/10.1177/0021998317726366

[28] Pereszlai, C. and Geier, N. (2020) Comparative Analysis of Wobble Milling, Helical Milling and Conventional Drilling of CFRPs. The International Journal of Advanced Manufacturing Technology, 106, 3913-3930.

https://doi.org/10.1177/0021998317726366

[29] Lipczynski, G., Eriksson, I. and Whinnem, E. (2009) Development of Orbital Drilling for the Boeing 787. SAE International Journal of Aerospace, 1, 811-816. https://doi.org/10.4271/2008-01-2317

[30] Ni, W. (2007) Orbital Drilling of Aerospace Materials. SAE Tech. Paper, 2007-01-3814. https://doi.org/10.4271/2007-01-3814

[31] Boehnke, D., Denkena, B. and Dege, J.H. (2008) Helical Milling of CFRP-Titanium Layer Compounds. The CIRP Journal of Manufacturing Science and Technology, $\mathbf{1}$, 64-69. https://doi.org/10.1016/j.cirpj.2008.09.009

[32] Liu, J., Chen, G., Ji, C., Qin, X., Li, H. and Ren, C. (2014) An Investigation of Workpiece Temperature Variation of Helical Milling for Carbon Fiber Reinforced Plastics (CFRP). International Journal of Machine Tools and Manufacture, 86, 89-103. https://doi.org/10.1016/j.ijmachtools.2014.06.008

[33] Rey, P.A., LeDref, J., Senatore, J. and Landon, Y. (2016) Modelling of Cutting Forces in Orbital Drilling of Titanium Alloy Ti-6Al-4V. International Journal of Machine Tools and Manufacture, 106, 75-88. 
https://doi.org/10.1016/j.ijmachtools.2016.04.006

[34] Budak, E., Altintas, Y. and Armarego, E.J.A. (1996) Prediction of Milling Force Coefficients from Orthogonal Cutting Data. Journal of Manufacturing Science and Engineering, Transactions of the ASME, 118, 216-224.

https://doi.org/10.1115/1.2831014

[35] Altintas, Y. (2000) Metal Cutting Mechanics, Machine Tool Vibrations, and CNC Design, Manufacturing Automation. Cambridge University Press, Cambridge. https://doi.org/10.1115/1.1399383

[36] Meng, Q.X., Zhang, K.F., Cheng, H., Liu, S.N. and Jiang, S.S. (2015) An Analytical Method for Predicting the Fluctuation of Thrust Force during Drilling of Unidirectional Carbon Fiber Reinforced Plastics. Journal of Composite Materials, 49, 699-711. https://doi.org/10.1177/0021998314525483

[37] Hosur, M.V., Chowdhury, F. and Jeelani, S. (2007) Low-Velocity Impact Response and Ultrasonic NDE of Woven Carbon/Epoxy-Nanoclay Nanocomposites. Journal of Composite Materials, 41, 2195-2212. https://doi.org/10.1177/0021998307074146

[38] Jong, H. (2006) Transverse Cracking in a Cross-Ply Composite Laminate-Detection in Acoustic Emission and Source Characterization. Journal of Composite Materials, 40, 37-69. https://doi.org/10.1177/0021998305053507

[39] de Albuquerque, Victor Hugo, C., Tavares Joao, M.R.S. and Durão, L.M.P. (2010) Evaluation of Delamination Damages on Composite Plates from Radiographic Image Processing Using an Artificial Neural Network. Journal of Composite Materials, 44, 1139-1159. https://doi.org/10.1177/0021998309351244

[40] Johnson, W., Treasurer, P. and Woodruff, G. (2008) Radiographic Investigation of the Effects of Ply Modification on Damage Development in Laminates Containing Circular Holes. Journal of Composite Materials, 42, 2143-2161. https://doi.org/10.1177/0021998308094552

[41] Chen, W. (1997) Some Experimental Investigations in the Drilling of Carbon Fibre-Reinforced Plastic (CFRP) Composite Laminates. International Journal of Machine Tools and Manufacture, 37, 1097-1108. https://doi.org/10.1016/S0890-6955(96)00095-8 